\title{
SOME OCCUPATIONAL EFFECTS OF NOISE
}

\author{
By DONALD STEWART (Birmingham)
}

Within British industry, with one or two notable exceptions, little significant research has been carried out on the occupational effects of noise on health or on human performance. The following introduction to one of these exceptions (Pollock and Bartlett, I932), although written nearly thirty years ago, still holds good today.

"The effects of intense and continuous noise on the human mind and body have been far more frequently a matter of popular comment than of scientific study. There appears to be a widespread opinion that noise directly diminishes efficiency, leads to increased liability to accidents, and provides a persistently favourable background for the development of nervous and mental disorders of many kinds. For all of these opinions there is very little evidence beyond the fact that noise tends to be disliked, particularly by people who are not very much accustomed to it."

In industry the problem of noise can be considered from several points of view: the effect on hearing and health, the effect on human performance, hearing conservation programmes, and methods of reducing noise.

\section{Effects on Hearing and Health}

Boilermakers' deafness was first described early in the nineteenth century, blacksmiths' deafness in I83I, and cotton-weavers' deafness in 1925. These are well-known classical examples of occupational deafness. But it was not until 1953 that further field studies were described about the auditory effects of noise exposure, not only in boilermakers but also in other factory groups such as drop-forgers and machine operators in the screw manufacturing industry (Johnson, 1953).

This survey was sponsored by the Medical Research Council under the general supervision of Terence Cawthorne, and I had the privilege of providing the field for investigation in factories where I acted as medical adviser. I was thus fortunate in having an opportunity to learn something about the effects of noise at first-hand during frequent discussions with the investigators.

Johnson showed that among 2 I9 men and women working in selected occupations known to be noisy, such as boilermaking and drop-forging, 28 suffered from bilateral ear disease of infective or degenerative origin 


\section{Donald Stewart}

not due to acoustic trauma; and of the remaining IgI cases all but one were found to have hearing losses due to noise which could be demonstrated either by speech or pure-tone audiometric tests. Noise measurements suggested that only when the overall noise level exceeded I05-Io8 phons is serious damage likely to be caused to hearing. This is the generally accepted view of other observers. At this level the ear must be protected by some suitable ear defender.

Personal impressions remain with me resulting from discussion both during and after this survey, with a number of the men concerned. With few exceptions boilermakers and drop-forge stampers were aware that deafness occurred in their industry. But this caused no worry nor was it considered in any way serious, it was just accepted as part of the job. The insidious course of their deafness had made them unaware of the degree of hearing loss. Many of the older men still had serviceable hearing, and some had learned to lip-read. Social experiences were interesting. Complaints of trouble or worry at home because of deafness were rare. Men were perfectly willing for their sons to enter their trade. Deafness was perhaps an excuse to avoid union meetings or going to church. Television had not yet "arrived", but the cinema was well patronized, more often for vision than the spoken word and a number confessed to lip-reading. Several men in the younger age groups with less exposure said that hearing improved after leaving work, particularly at weekends and during holidays.

During some 15 years the number of complaints of deafness which came to my notice among boilermakers and stampers was small. The men frequently asked that wax should be removed to make them hear better, and it did. Many of them had this done every 6-I2 months. A few preferred to retain their wax, for they felt it was a form of protection. Ear defenders although available were often discarded. Health complaints for other reasons were seldom linked with loss of hearing. Only on the rarest occasion was it held to be a cause of accident.

\section{Effects on Human Performance}

In I932 Weston and Adams published a report of controlled studies on the performance of operatives in a noisy Lancashire weaving shed. Performance was measured by recording the output of each loom. Where loom noise was reduced by using ear defenders the hourly average output per weaver in the group studied showed an increase of approximately one per cent. They therefore claimed to have established that noise could interfere with industrial output in this particular industry. They also showed that even after years of work in a noisy environment employees do not become completely adapted or acclimatized to noise but go on daily through the process of adaptation. During initial working periods when adaptation is minimal the average loss of output may be as high as 3 per cent. in individual cases. 


\section{Some Occupational Effects of Noise}

The experiment, the result of which has not so far been disproved, underlines the need for further work on the same subject. It seems probable that in other occupations with comparable noise intensities, but depending less on mechanical factors and more on the human factor, the effect of noise on output might be considerably greater than that demonstrated by this investigation.

The measurement of human performance provides many difficulties the most important of which is the unreliability of subjective assessments. Factors affecting performance are: labour turnover (that is the percentage of the total factory strength leaving each year); absence from work due to sickness, accident, or without leave; personal likes and dislikes caused by lack of satisfaction, by emotional factors, or by inadequate leadership; hours of work and type of work; and physical working conditions such as lighting, heating, ventilation, fumes or dust, and noise, all resulting in fatigue.

It can be seen therefore that the isolation of noise as the main cause or even as one cause of decreased output or of ill-health, is not by any means easy. Further research within this field is essential particularly in less noisy workplaces, and could come within the sphere of operational research now developing rapidly in various industries, assisted in the first place by research groups outside industry.

\section{Present-day Developments}

There is evidence of new activity on noise problems in Government departments and at research centres. Perhaps noise is no longer to be accepted as an inevitable part of modern living. A Noise Abatement Bill received its second reading in the House of Commons on the $4^{\text {th }}$ March, 1960. Although this deals particularly with the noise of road traffic it is perhaps relevant to this discussion. It is indicative of a public reaction which, through the Press, now demands action in the whole field of noise. And it highlights a major difficulty in promoting legislation to deal with the problem, namely the lack of an accurate method of measuring noise.

It is perhaps significant that the technical officers of the Ministry of Transport are said to be collaborating with the International Standards Organization to establish practical methods of estimating noise. But before coming to any conclusion the Ministry will no doubt seek the advice of various research bodies in this country, in particular the Department of Scientific and Industrial Research and the Medical Research Council.

An article on the problem of noise in industry (Times, London, April Ist, 1960) says that pocket-size sound-level noise-meters have recently been produced. These have been used in banks for noise surveys 


\section{Donald Stewart}

with apparent success as a first step to introducing methods of reducing the noise created by mechanization.

As an aside to the industrial problem it is interesting to know that the Southend Police have been using similar instruments to measure noise levels in evidence to support prosecutions of motorists and transport drivers. As another aside a recent report (Daily Telegraph, London, April 26th, 1960), said that the Italian manufacturers of the Vespa motorscooter had offered to make all their scooters now in use on Italian roads less noisy by fitting efficient silencers free of charge. But British dealers were opposed to this on the grounds that sales would drop, for many owners liked the noise.

It was reported recently (Lancet, April 23rd, 1960) that the Government had set up a committee "to consider noise and its effects". The committee includes two doctors, one a psychiatrist and the other a medical officer of health, but no otologist.

\section{Should Occupational Deafness be Classified as an Industrial Disease?}

This is primarily a question for the Government through the Ministry of Pensions and National Insurance. One difficulty is the identification of the cause as between the normal ageing process and specific occupations. A recent issue confronting otologists, and relevant to the question, is that claims may arise for monetary compensation because of potential loss of earnings where they advise job changes. Deafness is classified as an industrial disease in France, Germany, Finland and in Russia, but so far not in Great Britain. Under British legislation if occupational deafness is to be a "prescribed" disease, so also has the occupation to be "prescribed". Only thus can claims be made for loss of physical and mental faculty. And here the real difficulty arises. Occupational deafness would have to be treated as a risk of occupation and not as a risk common to all persons. Attribution of particular cases to the nature of the employment would have to be established. This is a matter which no doubt will be reviewed by the Industrial Injuries Advisory Council of the Ministry of Pensions and National Insurance on which medical experts serve as members as well as representatives of the trades unions and employers' associations.

\section{Medical Supervision at Work}

It has from time to time been suggested that what our American friends describe as a "hearing conservation programme" should be put into effect in noisy trades, and that this must be the final responsibility of the industrial medical officer. But before noise can be held to be hazardous in any occupational group it is essential that a survey of the noise conditions should be carried out. By whom this could be done, and from what source could the experts be drawn, are questions I would like to put 


\section{Some Occupational Effects of Noise}

to you. For example, could this come within the province of some new occupational hygiene laboratory service? In this country we have much to learn from American states where such laboratories are well-established and give a much needed service to local factories and business organizations.

A hearing conservation programme is held to include pre-employment aural history and ear examination, including pure-tone audiometry. Periodical re-examination would be essential. But again by whom could this best be done? By the industrial doctor alone, or with technical assistance, or under the guidance of a consulting otologist with a special interest in preventive medicine?

Are otologists ready or willing to enter this field? In addition to hospital and practice commitments would they be able to give time to initiate and supervise special training schemes for industrial medical officers? On one point let us be quite clear: without this training no hearing conservation programme in industry could be fully effective.

\section{Noise Suppression}

Extreme noise is relatively uncommon in industrial concerns. Where it occurs management in my experience appears to be anxious to take steps to reduce it, but not by spending large sums of money. Although deafness can probably be accepted as an occupational hazard in occupations such as boilermaking or aircraft engine testing, the degree of hazard has yet to be established in many other trades before employers can reasonably be advised to carry out extensive alterations to their plant and processes.

A noise suppression programme would basically include attempts at silencing, isolation, and sound-proofing, as well as the introduction of methods of ear protection. This immediately creates an interesting issue for the matter becomes a joint enterprise between employees, managers, engineers, and doctors. How often could we expect to find a suitably trained and experienced person within any industrial concern able to advise on this? Where could we find an individual outside industry able to act as a consultant in such matters? Would top management co-operate, particularly when it came to cost, for cost is an important obstacle to noise suppression? To what extent do architects and construction engineers consider the prevention of noise in their building projects? Are they fully aware of their responsibility in the matter? In their training is sufficient emphasis placed on the prevention of noise?

\section{Conclusion}

Little is known about the effects of noise on the health and efficiency of industrial workers apart from deafness. There is need therefore to implement the work of Johnson, and that of Weston and Adams, by 


\section{Donald Stewart}

operational research within industry, and where possible by industry. Assistance in this field should become available from otologists and experts in industrial health research, with the co-ordinated assistance of social workers, industrial psychologists, engineers and architects. One primary objective of such investigations should be the preservation of hearing.

\section{REFERENCES}

Johnson, C. M. (1953) Brit. J. industr. Med., 10, 4I.

Pollock, K. G., and Bartlett, F. C. (I932) Psychological Experiments on the Effects of Noise, Rep. industr. Hlth. Res. Bd. (Lond.), No. 65. p. I.

Weston, H. C., and Adams, S. (I932) The Effects of Noise on the Performance of Weavers, Rep. industr. Hlth. Res. Bd. (London.), No. 65, p. 38.

\footnotetext{
2 Hagley Court, Hagley Road, Birmingham, 16
} 